\title{
Políticas da morte: exercícios do poder e o coronavírus
}

\author{
Death policies: exercises of power and the coronavirus
}

\section{Regiane Lorenzetti Collares*; Luis Celestino de França Júnior**}

Resumo: Este artigo procura a partir do contexto da pandemia provocada pelo Coronavírus tecer articulaccões com o pensamento do filósofo francês Michel Foucault, em seu curso realizado no Collège de France, Segurança, Território e População (1977-1978), sobre as formas de exercício do poder e o tratamento dispensado às doenças epidêmicas. Como pano de fundo, tematizaremos também estratégias de governo pautadas tanto na manutenção das vidas, como na produção de mortos, identificando uma equação que visa atender prioritariamente a pressuppostos econômicos em detrimento da saúde da população.

Palavras-chave: Poder; Economia; Pandemia; População

Abstract: This article seeks, in the context of the pandemic caused by the Coronavirus, to articulate with the thought of the French philosopher Michel Foucault, in his course held at the Collège de France, Security, Territory and Population (1977-1978), about the ways of exercising power and the treatment of epidemic diseases. As a background, we will also focus on government strategies based both on the maintenance of lives and on the production of the dead, identifying an equation that aims primarily to meet economic assumptions to the detriment of the health of the population.

Keywords: Power; Economy; Pandemic; Population

Em um mundo com seus imperativos econômicos austeros, com elevadas exigências de produtividade, de investimentos que pedem um rápido retorno, em que perder é um verbo quase inconjugável e condenável, em que a maioria de tudo que vale a pena fazer se concilia com ganhar - de preferência com vantagem, com lucro -, uma outra condição de vida se impõe: nos vemos de repente em um contexto de paralisação e asfixia, agonizantes, prestes a entrar em colapso psíquico e físico dentro de um tempo desacelerado tão abruptamente e que nos restringe o movimento, e, o pior, há muito pouco que possamos fazer ou resolver, com o Coronavírus nos colocamos na situação-limite de questionar o próprio valor da vida, de nossa extrema dependência de um sistema econômico e, sobretudo, o preço de mantê-la.

Assim, nesta hora em que uma grande quantidade de vidas está posta em um contexto de eminente risco de morte, passa a prevalecer, e em nome da preservação da saúde da população, a confiança em um Estado com suas medidas disciplinares, que pela alegação de nos proteger da contaminação em massa, por um lado, determina fecharem as escolas, universidades, creches, as portas da nossa própria casa, nos recomendando o recolhimento em quarentena, não andar nas ruas, passear, não tomar um ar nas praças e parques, evitar o contato público, por outro lado, também nos compele a uma retomada, muitas vezes precipitada, da atividade econômica, sob a lógica de que o mercado mundial não pode parar, nos impondo uma espécie de superego econômico que é admoestador frente a demora de uma volta à vida "normal".

Entretanto, nos Estados, em seus planos de governamentalidade, parece que a prioridade de salvar a economia ainda prevalece ante a missão de salvar vidas, e há uma conta que não conseguimos ainda calcular quando relacionada às tomadas de decisão por parte da racionalidade econômica em seu íntimo compromisso com o sistema financeiro e que muito

\footnotetext{
Professora Associada de Filosofia na Universidade Federal do Cariri, Juazeiro do Norte, CE. E-mail: regiane.collares@ufca.edu.br ORCID: https://orcid.org/0000-0002-3066-1163

** Professor na Universidade Federal do Cariri, Juazeiro do Norte, CE. E-mail: luis.celestino@ufca.edu.br ORCID: https://orcid.org/0000-0003-0312-5063
} 
nos angustia, não apenas por imaginar o alto valor a ser pago, como, sobretudo, por indagar quem afinal vai pagar a batalha contra o Covid-19. Como constatam Dardot e Laval a respeito das atitudes dos Estados diante dos efeitos catastróficos do Coronavírus na esfera econômica:

O Estado agora não tem mais escrúpulos em gastar sem limite para 'salvar a economia' (usa o que for preciso) (...) Havia um respeito obsessivo pelas restrições orçamentárias e pelos limites da dívida pública. Hoje, os Estados parecem redescobrir as virtudes da intervenção, pelo menos quando se trata de apoiar a atividade de empresas privadas e garantir o sistema financeiro ${ }^{1}$.

Talvez seja prematuro considerar quais os efeitos da pandemia no alicerce neoliberal da política global, no entanto, é necessário questionar não a sua ruína - tanto o Covid-19 como o capital parecem ser muito resistentes - , mas, suas mutações, suas defesas, sua força de expansão em um mundo de antemão contaminado, de forma muito mais letal do que pelo Coronavívus, pelo capital fluido que não conhece barreiras e se expande por todos os territórios, com o poder de disseminação dependente de uma maquinaria política e biológica, que agora se vincula a uma decisão governamental sobre os que devem pagar a conta pelo prejuízo decorrente da pandemia, quem se deve excluir, isolar, para, por fim, não apenas deixar morrer, como também fazer morrer. Neste sentido, este artigo cumpre a partir do curso Segurança, Território e População, realizado pelo pensador francês Michel Foucault, no Collège de France, analisar de que forma os governos para tratar de grandes epidemias se valem de prerrogativas econômicas para intervenção no destino das vidas nas cidades.

\section{Doença, cidade e vidas}

É surpreendente a atualidade das considerações de Foucault feitas há mais de 40 anos em seu curso Segurança, Território e População, no Collège de France, sobre a relação entre doenças viróticas, que assolaram a humanidade pela alta incidência de mortalidade, e os modos de poder e de governo. Neste curso podemos encontrar um material de pesquisa que demarca uma mudança de técnicas de governo e de gestão da economia com a mobilização que se deu para lidar com epidemias como a lepra, a peste e a varíola. Para cada epidemia, tanto a varíola na modernidade, como a lepra e a peste, em que os grandes surtos ocorreram por volta dos séculos XVI e XVII, respectivamente, identificou-se uma correlação de um modo de tratar a doença e os modos de se governar.

Atento à relação íntima das proposições econômicas com a gestão de espaços e dos doentes contaminados, Foucault, neste curso, vai começar por identificar um modo de poder soberano de incidir sobre a vida dos doentes acometidos pela lepra. Em um contexto geral, com o poder soberano se exerceram mecanismos de governo que se detiveram em agir nos limites do território, pois, a maioria das cidades nos séculos XVI e XVII eram essencialmente caracterizadas por um isolamento jurídico-administrativo dentro de um espaço "murado e denso", em que as atividades econômicas e sociais se voltavam para uma dimensão campesina. Desse modo, na ocasião do acometimento da lepra, os doentes eram simplesmente confinados para morrerem longe dos não contaminados, se empreendendo a exclusão, separação rigidamente binária dos contaminados daqueles que não estavam contaminados, operacionalizando-se para isso um conjunto jurídico, "de leis, de regulamentos, conjunto religioso e também de rituais"2.

Em acordo com a pesquisa foucaultiana em um texto de meados do século XVII, escrito por Alexandre Le Maître, intitulado Le Métropolitée, os problemas que surgiram nas cidades

\footnotetext{
1 DARDOT; LAVAL, L'éprouve politique de la epidèmie, Disponível em https://blogs.mediapart.fr/lesinvites-de-mediapart/blog/190320/l-epreuve-politique-de-la-pandemie Acesso em19/03/2020 2 FOUCAULT, Segurança, Território e População, p. 13
} 
com um modo de poder soberano se deram a partir do crescimento do comércio, da necessidade de intercâmbios econômicos e do adensamento populacional no interior das muralhas, tudo isso demandou um "desencravamento espacial, jurídico, administrativo, econômico da cidade" para ressituá-la em um novo espaço de circulação ${ }^{3}$. Com a determinação da necessidade deste novo espaço de circulação, o território vai ser dividido em partes muito bem demarcadas em suas ordens, como a reserva de um espaço restrito à circulação dos soberanos e seus oficiais, outro espaço para os artesãos e, por fim, um para os camponeses. Nessa disposição arquitetônica, a capital do Estado deveria estar no centro da cidade, sendo que a eficácia política, segundo Le Maître, estaria ligada a uma intensidade de circulação, tanto de ideias, como das vontades, das ordens, do comércio etc.

Para atender esta disposição das pessoas na cidade empreende-se então um poder disciplinar, prevalecendo o controle da circulação nos espaços demarcados para a garantia da segurança, evitando-se assim as aglomerações desordenadas com a abertura de espaços livres para as relações comerciais que seriam regulamentadas por instâncias administrativas. Com este tipo de cidade surgem a reboque desta disposição territorial as demandas governamentais de higiene, de garantia do comércio no interior da cidade, de rede de ruas para o fluxo de mercadorias e, o mais importante para as cidades no século XVIII, da vigilância para garantir a segurança mesmo com a eliminação das muralhas. A alternativa à época foi se utilizar de um poder disciplinar para "organizar a circulação, eliminar o que era perigoso nela, de separar a boa circulação da má, maximizar a boa circulação diminuindo a má"4, controlando os corpos em uma estrutura hierárquica e funcional.

Com a peste, surgida no contexto deste poder disciplinar, o tratamento dos doentes irá se diferenciar do tratamento da lepra pelo poder soberano, consistindo não mais em deixar os doentes retidos em espaços de confinamento, mas em fazer valer rígidos regulamentos aplicados aos infectados como orientar seus hábitos, cercear seus movimentos com a prática da quarentena, a fim de evitar o contágio massivo e conseguir maior eficiência em isolar as pessoas contaminadas. Comenta Foucault sobre os regulamentos dispostos no caso da peste:

quadrilhar literalmente as regiões, as cidades no interior das quais existe a peste, com uma regulamentação indicando às pessoas quando podem sair, como, a que horas, o que devem fazer em casa, que tipo de alimentação devem ter, proibindo-lhes este ou aquele tipo de contato, obrigando-as a se apresentar a inspetores, a abrir a casa aos inspetores ${ }^{5}$.

Daí em diante, num deslocamento paulatino das medidas disciplinares frente ao surgimento dos grandes conglomerados populacionais, o poder se transmuta em tecnologias mais eficientes de contenção e controle da população, e a questão da segurança passa a ser a tônica de um poder que vai se ocupar de projeções, estimativas, não mais de um futuro controlado e controlável, mas fazendo seu planejamento em cima do que pode acontecer à população, das probabilidades de uma intempérie prejudicar a vida na cidade. Nesta modalidade de poder que é o biopoder, poder ocupado da vida, vai se procurar não mais atingir os corpos, vigiá-los, mas incidir na multiplicidade de indivíduos que existem materialmente ligados à condição biológica de seres viventes. Por conseguinte, com o aparecimento da varíola, no século XVIII, os dispositivos de segurança vão se aprimorando a reboque da doença, não sendo mais necessário uma regulamentação para a separação entre os doentes e os não-doentes, surgindo assim um mecanismo que levaria em conta o conjunto da população "sem descontinuidade, sem ruptura, dos doentes e não-doentes"6.

\footnotetext{
${ }^{3}$ FOUCAULT, Segurança, Território e População, p. 17

${ }^{4}$ FOUCAULT, Segurança, Território e População, p. 24

${ }^{5}$ FOUCAULT, Segurança, Território e População, p. 13

${ }^{6}$ FOUCAULT, Segurança, Território e População, p. 81
} 
A este mecanismo, como um tipo de variação dos dispositivos de segurança, se acrescentará outra estratégia que não a disciplina, com sua onerosa exigência de constante vigilância e manutenção de espaços de isolamento, a saber, esta nova técnica consistiu em fazer prospecções estatísticas de população, estabelecendo-se com isso uma curva "normal" dos casos de infecção ou morte pela doença, fazendo os governos em face da doença já previamente contar e administrar o número de contaminados e índices de mortalidade a partir da adesão da população à inoculação do vírus da varíola7. Então, no caso da varíola, embora a disciplina muitas vezes seja "chamada em auxílio", esta tecnologia de governo já não teria tanta eficácia para o controle da população, a questão não seria manter as pessoas sob vigilância, mas saber em índices estatísticos "quantas pessoas pegaram varíola, com que idade, com quais efeitos, qual a mortalidade, quais as lesões ou quais as sequelas, que riscos se corre fazendo-se inocular"8.

É na aula de 25 de janeiro que Foucault vai discorrer sobre a epidemia da varíola como uma forma de tratar da integração da doença a um plano racionalizado de governamentalidade. Vejamos:

A partir do momento em que, a propósito da varíola, passam a ser feitas as análises quantitativas de sucessos e insucessos, de fracassos e de êxitos, quando passam a calcular as diferentes eventualidades de morte ou de contaminação, então a doença não vai mais aparecer nesta relação maciça da doença com o seu lugar, seu meio, ela vai aparecer como uma distribuição de casos numa população que será circunscrita no tempo ou no espaço9.

Com a noção de casos, do aumento ou diminuição do número de casos, há um modo de quantificação, "do racional e do identificável" para se integrar no âmbito coletivo os casos individuais. Somente em referência ao número de casos, se tornam mais aceitáveis um conjunto de normatizações; "aceitáveis para os médicos, para os administradores, para os encarregados da 'polícia médica' e, finalmente, para as próprias pessoas"10.

Foucault, observante da integração de tecnologias de segurança voltadas para a doença, vê nelas uma espécie de adaptação de mecanismos econômicos para as estratégias de governo que visariam um tratamento quantitativo da população, e passa a identificar além da noção de caso, as noções de risco, de perigo e de crise como parte de um arsenal governamental. Estas noções em conjunto vão justificar as mais diversas medidas de governo no que concerne ao modo de vida levado na cidade.

Por exemplo, com a noção de risco se estabelece para cada indivíduo ou grupo individualizado a chance de se contrair a doença, morrer ou mesmo se curar; "para cada indivíduo, dada a sua idade, dado o lugar em que mora, pode-se igualmente para cada faixa etária, para cada cidade, para cada profissão, determinar o risco de morbidade, o risco de mortalidade"11. Se o cálculo de riscos mostra que eles não são os mesmos para todas as pessoas, variando de acordo com a idade, condições prévias de saúde, condições climáticas, etc, obviamente nas incidências de maior risco identifica-se àquilo que é mais perigoso em termos de contaminação e letalidade. Com uma reflexão mais abrangente acerca dos riscos, da probabilidade de riscos e suas repercussões emocionais, Brian Massumi afirma "Se os riscos podem ser calculados em termos de probabilidade, estas últimas não têm nada a dizer sobre

\footnotetext{
${ }^{7}$ A técnica de inoculação ou variolização, uma prática originalmente oriental, começou a ser exercida na Europa a partir do século XVIII, e consistia em implantar o vírus da varíola no homem saudável, provocando a instalação virótica em uma forma mais branda e com manifestação local, para forçar o organismo a fabricar anticorpos para a doença.

${ }^{8}$ FOUCAULT, Segurança, Território e População, p. 14

${ }^{9}$ FOUCAULT, Segurança, Território e População, p. 79

${ }^{10}$ FOUCAULT, Segurança, Território e População, p. 78

${ }^{11}$ FOUCAULT, Segurança, Território e População, p. 79
} 
cada caso em particular". Entretanto, saber dos riscos é determinante para conter ou refrear uma atitude individual, Massumi adverte então que as escolhas tomadas a partir de um quadro de riscos "são altamente carregadas, em um plano afetivo, pelo medo de um futuro incerto. 0 presente é abalado pelo futuro ao ponto de tremer. Não há cálculo de risco que seja independente da relação afetiva que o indivíduo possui consigo em relação à incerteza" 12 .

Com a noção de risco, coloca-se em questão a noção de perigo, sendo ambas promissoras em potencializar a adesão da população às medidas de governo. 0 perigo deixa a população constantemente em alerta, pois qualquer variação brusca do surto da doença pode vir a deflagrar a condição de crise. Portanto, no rastro do risco e do perigo vem a instauração da crise.

A crise nada mais é, nas palavras de Foucault, do que

fenômenos de disparada, de aceleração, de multiplicação da doença num momento dado, num lugar dado, possa vir, por meio do contágio, a multiplicar os casos que, por sua vez, vão multiplicar outros casos, e isso segundo uma tendência, uma curva que pode vir a não mais se deter, a não ser que, por um mecanismo artificial, ou também por um mecanismo natural porém enigmático, possa ser controlada e o seja efetivamente ${ }^{13}$.

Diante desses fenômenos de disparata em que se identifica uma crise, a população tende a apostar todas as fichas em um mecanismo superior que possa detê-la ou em uma intervenção artificial que possa controlá-la. Na época em que Foucault se debruçou na análise das noções de caso, risco, perigo e crise, ele passou a vê-las como um novo campo de aplicação de técnicas de segurança por parte do governo para intervir diretamente no controle da população. Entretanto, é importante enfatizar que, ainda segundo os estudos foucaultianos deste assunto, não existe uma sucessão de tecnologias de governo ao longo da história, em que um modo de poder vai pura e simplesmente suplantar o anterior; um modo de governo pautado na segurança faria funcionar não apenas dispositivos próprios da segurança, mas de certa forma acrescentaria "as velhas estruturas da lei e da disciplina"14. Ou seja, não há ruptura e sim acréscimo, tecnologias diferenciadas vão se acoplando a fim de sustentar uma economia geral de poder, e o que vai diferenciar entre um mecanismo de governo e outro vai ser o modo com que são operacionalizados estes poderes.

\section{A peste e o homo oeconomicus}

Como vimos, se o poder soberano, como no caso da lepra, na inflexão de um "poder absoluto e dramático", consistiu na radicalidade de fazer morrer, isolar os doentes para que pudessem morrer sozinhos e sem maiores cuidados, com as tecnologias do biopoder, cumpre, ao contrário, considerar o homem como ser vivo, fazê-lo viver por um "poder contínuo e científico". Aí a célebre equação foucaultiana elaborada já Em Defesa da Sociedade, em 1976: "A soberania fazia morrer e deixava viver. E eis que agora aparece um poder que eu chamaria de regulamentação e que consiste, ao contrário, em fazer viver e deixar morrer" 15.

Com esta modalidade de poder se cria então o direito de os Estados intervirem para fazer viver, uma maneira de viver, um "como" viver. Podemos a partir daí identificar a implicação íntima entre fluxo econômico e política que se ocupa da vida; a biopolítica que surge tem como prioridade um fazer viver conforme as demandas da economia. Foucault, em Nascimento da Biopolítica, curso realizado entre o final de 1978 e começo de 1979, também no

\footnotetext{
12 MASSUMI, L'Économie contre Elle-Même, p.51

13 FOUCAULT, Segurança, Território e População, pp.80-81

${ }^{14}$ FOUCAULT, Segurança, Território e População, p. 14

15 FOUCAULT, Em Defesa da Sociedade, p.294
} 
Collège de France, destaca assim uma nova forma de relações que possui lógica própria e que começou a caracterizar um dos mais importantes efeitos do neoliberalismo nas formas de governar e de viver, a saber, a concorrência. Muito mais do que um princípio de relações econômicas, a concorrência ultrapassaria as relações entre governo e população, "possuindo uma lógica interna", um "jogo formal entre desigualdades"16.

Sob o primado da concorrência, o homo oeconomicus emergente vem se apoiar em uma condição de vivência e convivência pautadas em relações econômicas, em que "se aceita a realidade" a partir de uma conduta racional que é sensível "a modificações nas variáveis do meio e que responde a elas de forma não-aleatória, de forma portanto sistemática"17. 0 homo oeconomicus surge então como um ser manejável e governável, pois sua razão de ser se atrela à economia, servir aos seus próprios interesses coincide com obedecer a economia; o homo oeconomicus deixa a dimensão do laissez-faire do liberalismo clássico e vai se entrelaçar com uma governamentalidade que age sobre o meio e o modifica.

Pierre Dardot e Christian Laval afirmam em concordância com a leitura foucaultiana sobre o primado das relações pautadas na concorrência no mundo contemporâneo e afinadas com as considerações biológicas de Hebert Spencer, a quem consideram o representante científico de uma "virada" na história do liberalismo pela ideia da luta pela sobrevivência na esfera social, que

nada garante que aquele que participa da grande luta da seleção natural irá sobreviver, apesar de seus esforços, de sua boa vontade, de suas capacidades. Os menos aptos, os mais fracos, serão eliminados por aqueles que são mais adaptados, mais fortes na luta. Não se trata mais de uma lógica de promoção geral, mas de um processo de eliminação seletiva ${ }^{18}$.

Este evolucionismo spenceriano vai ao encontro de uma das principais premissas do neoliberalismo na inflexão da biopolítica: que o progresso da sociedade vem se atrelar à condição de constante competição entre seus membros e a eventual eliminação e destruição de alguns. Sendo assim, levadas pelas transformações do capitalismo, as biopolíticas visam empreender todo um sistema de coação econômica e social, cuja função é "obrigar os indivíduos a governar a si mesmos sob a pressão da competição, segundo os princípios do cálculo maximizador e uma lógica de valorização de capital"19.

Vale salientar que houve a ampliação das técnicas disciplinares no que diz respeito à governamentalidade biopolítica, imiscuindo-se nelas uma racionalidade geral, um regime de evidência propagado pelos governos como base de compreensão das ações humanas. Este regime de evidência obriga todo indivíduo a participar de um cálculo no que diz respeito às escolhas e aos resultados previamente estabelecidos como símbolos de êxito e de bem-estar. Nesta perspectiva, uma racionalidade política não se dá como um conhecimento neutro de que os governos se valem para intervir na população, na verdade, esta racionalidade cria um campo discursivo para os governos exercerem o poder. Isso acontece por meio da escolha de um objeto, de uma causa a problematizar, para depois oferecer certas estratégias para se não resolver pelo menos administrar uma crise.

Com a dimensão da crise, constitui-se então uma engrenagem ativada pelos governos para a responsabilização dos indivíduos pelo cálculo errado que tiveram na vida, traduzindo suas ações em um valor contábil, com indicadores comparativos. Sob um contexto de competitividade, cada indivíduo no final das contas é responsabilizado pelo seu fracasso, desobrigando os Estados de promoverem políticas públicas eficientes. Dardot e Laval comentam o seguinte:

16 FOUCAULT, Nascimento da Biopolítica, p. 163

17 FOUCAULT, M. Nascimento da Biopolítica, p.368

18 DARDOT, LAVAL, A Nova Razão do Mundo, p.53

19 DARDOT, LAVAL, A Nova Razão do Mundo, p.193 
A problemática da saúde, da educação, do emprego, e da velhice confluem numa visão contábil do capital que cada indivíduo acumularia e geraria ao longo da vida. As dificuldades de existência, a desgraça, a doença e a miséria são fracassos dessa gestão, por falta de previsão, prudência, seguro contra riscos. Daí o trabalho pedagógico que se deve fazer para que cada indivíduo se considere como um detentor de "capital humano" que ele deve fazer frutificar, daí a instauração de dispositivos que são destinados a "ativar" os indivíduos, obrigando-os a cuidar de si mesmos, educar-se, encontrar um emprego ${ }^{20}$.

Destarte, a partir de uma racionalidade tirada do quadro de cálculos que servem ao máximo proveito de um sistema econômico, na proliferação do capital, as ações políticas ganharam dimensões deletérias, e agora não se conta mais exclusivamente com a fórmula enunciada por Foucault de "fazer viver e deixar morrer". Temos hoje uma necropolítica em curso, uma política de extermínio, que é eficiente em fazer morrer. Esta política da morte denunciada principalmente por Achille Mbembe, em seu livro Necropolítica, de certa forma reativa um poder soberano que é promissor pelo uso de técnicas "mais trágicas" de policiamento e disciplina devido ao extremismo das ações da racionalidade governamental.

"Tecnologias de destruição tornaram-se mais táteis, mais anatômicas e sensoriais, dentro do qual a escolha se dá entre a vida e a morte", afirma Mbembe, sendo que se ainda o poder incide sobre os corpos, agora, em acordo com a versão mais cruel e agonística de economias neoliberais, coloca-se a necessidade do empreendimento de fossos de distanciamento e isolamento no conjunto da população, verdadeiras trincheiras em que se encerra um "resto" populacional em zonas marginais, de invisibilidade, com o objetivo de um massacre silencioso, justamente porque a questão política é "inscrevê-los, no momento oportuno, na ordem da economia máxima, agora representada pelo "massacre"21.

No caso dos massacres, na sua "generalidade indiferenciada", os corpos sem vida caem como corporeidades vazias; sem nome, sem família, sem identificação, sem história. Já em relação aos que sobrevivem, como compreende o filósofo italiano Giorgio Agamben, também se cai em uma zona de indistinção. Se na política clássica se distinguia entre zoé, vida natural ou vida nua, e bios, vida política, na atualidade, um estado de exceção se tornou regra, a saber, que nosso corpo biológico seja indistinguível de nosso corpo político, "que experiências que há um tempo se diziam políticas fossem, de repente, confinadas no nosso corpo biológico e que experiências privadas se apresentassem subitamente fora de nós como corpo político" 22 . As consequências da primazia da zoé, nas configurações mais tardias provindas da biopolítica, é que a "vida nua" que estava contida em sua condição de marginalidade e o mais distante possível das ocupações políticas, passa a ser o objeto de uma decisão soberana: decidir aqueles que devem viver e os que devem morrer.

Assim, no caso do Covid-19, o vírus nos acomete em um contexto em que a primazia em fazer morrer ultrapassa o cálculo governamental de deixar morrer. 0 número de excluídos, de pessoas que sobrevivem em condições econômicas precárias, políticas de genocídio em escala mundial, não deixa de convulsionar toda a racionalidade política. Nos vemos desnorteados em um labirinto que somos conduzidos pelo fio perigoso de imperativos econômicos a becos sem saída, nos quais nos isolamos, nos perdemos de vista e nos vemos sem futuro.

No livro de Albert Camus, A Peste, escrito em 1947, é narrado o sofrimento que se abateu sobre a população de Orã, na Argélia, devastada pela contaminação da peste, alusão também à invasão do exército alemão em Paris. A personagem principal, Dr. Rieux, médico que cuida obstinadamente dos doentes, assim descreve o sentimento que se abateu sobre a cidade depois que a doença passou:

\footnotetext{
20 DARDOT, LAVAL, A Nova Razão do Mundo, pp. 230-231

${ }^{21}$ MBEMBE, Necropolítica, p.59

22 AGAMBEN, Meios sem Fim, p.124
} 
Chegados ao fim da peste, com a miséria e as privações, todos esses homens acabaram assumindo o traje do papel que desempenhavam já havia muito tempo: o de emigrantes cujo rosto, primeiro, e agora as roupas falavam da ausência da pátria longínqua. A partir do momento em que a peste fechou as portas da cidade, tinham vivido somente na separação, afastados desse calor humano que faz esquecer tudo. Em graus diversos, em todos os cantos da cidade, esses homens e essas mulheres tinham aspirado a uma reunião que não era para todos da mesma natureza, mas que para todos era igualmente impossível. A maior parte tinha gritado com todas as suas forças por um ausente, o calor de um corpo, a ternura ou o hábito ${ }^{23}$. crônica

E, então, não apenas depondo a favor das vítimas da peste, assume que escrevera sua para deixar ao menos uma lembrança da injustiça e da violência que lhes tinham sido feitas e para dizer simplesmente o que se aprende no meio dos flagelos: que há nos homens mais coisas a admirar que coisas a desprezar.

Mas ele sabia, porém, que esta crônica não podia ser a da vitória definitiva. Podia, apenas, ser o testemunho do que tinha sido necessário realizar e que, sem dúvida, devemos realizar ainda, contra o terror e sua arma infatigável ${ }^{24}$.

A despeito da crítica foucaultiana julgar ingênua a visão camusiana do homem, do homem que, por sua liberdade e consciência e alheio aos atravessamentos da história e das tramas de poder em sua constituição, se volta contra o mundo, vale a pena aqui, em um tempo de pandemia, resgatar a sua imagem literária da contaminação de uma cidade por uma doença contagiosa, utilizá-la como uma metáfora oportuna menos por salientar o caráter absurdo da existência, de nossa condenação à morte, da nossa revolta, do que pelo alerta ante a ameaça política sobre as populações acometidas pelo vírus. 0 "testemunho do que tinha sido necessário realizar e que, sem dúvida, devemos realizar ainda, contra o terror e sua arma infatigável" do Dr. Rieux nos instiga a pensar na continuação da cidade nas relações de uns com os outros, dos agenciamentos de vidas, das conexões afetivas que ainda são possíveis estabelecer, para além de qualquer imposição econômica e restrição de segurança que nos limita e cerceia o contato. Refletir em tempo de isolamento social para enfrentar uma doença, neste caso, pode ser o recuo necessário para novas articulações de cuidado conosco e com os outros, inocular o coronavírus simbolicamente talvez seja um caminho interessante para produzirmos anticorpos que tanto nos fortifiquem no enfrentamento das pestes contemporâneas, do desemprego, da miséria, do massacre de minorias, como nos potencializem para buscar alternativas criativas de proposições éticas e políticas que consigam ultrapassar os cálculos econômicos.

\section{Referências}

AGAMBEN,G. Meios sem Fim: Notas sobre a Política. Belo Horizonte: Editora Autêntica, 2015. CAMUS, A. A Peste. Rio de Janeiro: BestBolso, 2016

DARDOT, P e LAVAL, C. A Nova Razão do Mundo. São Paulo: Boitempo, 2016

DARDOT, $\mathrm{P}$ e LAVAL, C. L'éprouve politique de la epidèmie. Disponível em: https://blogs.mediapart.fr/les-invites-de-mediapart/blog/190320/l-epreuve-politique-de-lapandemie Acesso em19/03/2020

23 CAMUS, $A$ Peste, p.281

${ }^{24}$ CAMUS, $A$ Peste, p.290 
FOUCAULT, M. Em Defesa da Sociedade. São Paulo: Martins Fontes, 2005.

FOUCAULT, M. Nascimento da Biopolítica. São Paulo: Martins Fontes, 2008.

FOUCAULT, M. Segurança, Território e População. São Paulo: Martins Fontes, 2008.

MASSUMI, B. L'Économie contre Elle-Même. Québec: Lux Éditeur, 2018.

MBEMBE, A. Necropolítica. São Paulo: N-1Edições, 2018. 